IZA DP No. 6374

The Impact of Migration on Family Left Behind

Francisca M. Antman

February 2012 


\title{
The Impact of Migration on Family Left Behind
}

\author{
Francisca M. Antman \\ University of Colorado at Boulder \\ and IZA
}

\section{Discussion Paper No. 6374 February 2012}

\author{
IZA \\ P.O. Box 7240 \\ 53072 Bonn \\ Germany \\ Phone: +49-228-3894-0 \\ Fax: +49-228-3894-180 \\ E-mail: iza@iza.org
}

\begin{abstract}
Any opinions expressed here are those of the author(s) and not those of IZA. Research published in this series may include views on policy, but the institute itself takes no institutional policy positions.

The Institute for the Study of Labor (IZA) in Bonn is a local and virtual international research center and a place of communication between science, politics and business. IZA is an independent nonprofit organization supported by Deutsche Post Foundation. The center is associated with the University of Bonn and offers a stimulating research environment through its international network, workshops and conferences, data service, project support, research visits and doctoral program. IZA engages in (i) original and internationally competitive research in all fields of labor economics, (ii) development of policy concepts, and (iii) dissemination of research results and concepts to the interested public.
\end{abstract}

IZA Discussion Papers often represent preliminary work and are circulated to encourage discussion. Citation of such a paper should account for its provisional character. A revised version may be available directly from the author. 
IZA Discussion Paper No. 6374

February 2012

\section{ABSTRACT}

\section{The Impact of Migration on Family Left Behind ${ }^{*}$}

This paper addresses the effects of migration on families left behind and offers new evidence on the impact of migration on elderly parents. After discussing the identification issues involved in estimation, I review the literature on the effects of migration on the education and health of non-migrant children as well as the labor supply of non-migrant spouses. Finally, I address the impact of adult child migration on contributions toward non-migrant parents as well as the effects on parental health. Results show that elderly parents receive lower time contributions from all of their children when one child migrates.

JEL Classification: O15, D13, J13, J14, F22, I15, I25

Keywords: migration, left behind, elderly, children

Corresponding author:

Francisca M. Antman

Department of Economics

University of Colorado at Boulder

256 UCB

Boulder, CO 80309

USA

E-mail: Francisca.Antman@colorado.edu

\footnotetext{
* Prepared for International Handbook on the Economics of Migration. I am grateful to the editors, Klaus Zimmermann and Amelie Constant, as well as an anonymous referee, for their feedback and suggestions. Portions of this research were supported by the Leonard W. Ely and Shirley R. Ely Graduate Student Fund through a grant to the Stanford Institute for Economic Policy Research. I thank Doug Bernheim for his guidance and advice on the simulation exercise. All errors are my own.
} 


\section{INTRODUCTION}

It is now well-accepted that international migration can have important consequences for sending countries as well as receiving areas. The direction and magnitude of these effects, however, are increasingly investigated and not yet fully understood. Since origin countries are typically part of the developing world, these studies have particular importance because they coincide with the interest in economic development more broadly.

One relatively new feature of research on the impact on sending areas is a focus on the separation of families that migration so often implies. This may take many forms, whether it is an entire nuclear family separating from extended family in the source country or a parent or child migrating alone with dependents left behind. In many parts of the world, this type of migration is circular and recurrent ${ }^{1}$, raising questions about the impact of migration on family members left behind and their reliance on the migrant for support.

This chapter focuses on the direct impact of international migration on the families of migrants that are left behind in source countries. More specifically, this chapter focuses on the impact of migration on non-migrant children, spouses, and parents who are left behind.

The remainder of the chapter is structured as follows. Section 2 discusses the methodological problems inherent in estimating the effects of migration on the left behind and the empirical solutions that have been proposed in the literature. Section 3 reviews the literature on the effects of migration on children left behind, with a focus on outcomes related to education and health. Section 4 surveys the literature on the effects of migration on the labor supply of spouses left behind. Section 5 discusses the impact of migration on the financial and time 
assistance going to non-migrant parents left behind as well as the impact on parental health. Section 5.3 presents a case study in which I simulate the contributions to parents from all of their children in the case where one child migrates to the U.S. and the case where all children remain in Mexico. The evidence suggests that time contributions to parents fall when one child migrates while the results for financial contributions are more ambiguous. Section 6 concludes.

\section{EMPIRICAL PROBLEMS AND PROPOSED SOLUTIONS}

The main methodological problem in studies of the impact of migration on family members left behind is typically the endogeneity of migration itself. Since migration is generally not random and migrants self-select, it is generally acknowledged that migration is likely to be correlated with the same factors that influence outcomes for family members left behind. Thus, it becomes difficult to determine whether migration is causing the outcome of interest or whether it is some other lurking variable that is correlated with both migration and the outcome of interest. In short, there is a classic omitted variable problem.

For instance, if migration is costly, families that are better off socio-economically may be better able to afford migration for one of their members and also pay for educational expenses of their children (Kuhn, 2006). Thus, a cross-sectional comparison of households with migrant members and households without may pick up the effect of higher socio-economic status (SES) instead of the effect of the actual migration. While some researchers have used propensity score matching (PSM) methods (Alaimo, 2007; Kuhn et al., 2011) to address the endogeneity problem, these approaches assume that selection into migration is based on observables, and thus are still vulnerable to the omitted variable problem. 
Other studies have used some variant of fixed-effects estimators to net out any observed and unobserved variation that is common within families or to individuals (Antman, 2011c). These methods are only helpful, however, if the omitted variable is thought to be constant at the family or individual level, and not expected to vary over time. For example, if migration is again assumed to be costly, a family with an unexpected improvement in SES would be better able to finance both migration and children's education or health investments. But if the improvement in SES were not observable to the researcher, he might falsely conclude that migration had caused the improved outcomes for children in the household, when in fact it should be attributed to the positive economic shock.

A related problem in observational studies may also be one of reverse causation, wherein the observed outcome is actually causing the migration event, rather than the other way around. This could be the case in cross-sectional data sets where migration occurred before the start of the survey and thus researchers may be observing the circumstances which precipitated the migration, rather than the effects of migration on the family's circumstances. Longitudinal data where researchers can observe outcomes before and after the migration event takes place pose a possible solution to this problem, but again are still vulnerable to the possibility that some unobserved time-varying shock is responsible both for the migration event and the outcome of interest.

Given the problems with cross-sectional and even longitudinal approaches, researchers have turned to instrumental variables (IV) estimators to estimate the effects of international migration of one individual on outcomes for family members left behind. Of these studies, the major stumbling block is finding a valid instrument that only affects the outcome of interest 
through its effect on the migration variable. This is indeed a high (and ultimately untestable) bar for an instrumental variable and the search for one becomes even more problematic since variables that are arguably exogenous are usually more likely to be weakly correlated with the outcome of interest. Thus, it is no surprise that several studies have converged on a small set of the least controversial instruments. Of the instrumental variables that have been used in the literature on the impact of migration on the left behind, the most popular appear to be historical migration rates (Hanson and Woodruff, 2003; Hildebrandt and McKenzie, 2005; McKenzie and Rapoport, 2011) and variables linked to economic conditions in destination areas (AmuedoDorantes and Pozo, 2010; Amuedo-Dorantes et al., 2008; Cortes, 2010; Antman, 2011b; Yang, 2008).

The gold standard in empirical research, however, remains the randomized trial and recent research efforts have brought this methodological advantage to bear on understanding the impact of migration on the left behind. Mergo (2011) exploits the Diversity Visa lottery program to evaluate the effects of international migration on families left behind in Ethiopia. Non-migrant family members of visa winners who migrated to the U.S. are found to have better living standards than families of non-winners.

Gibson et al. (2011a) present wide-ranging results from a migration lottery program in New Zealand that allows them to compare families of successful applicants who were authorized to migrate with families of unsuccessful applicants that were not. The main drawbacks of the study are the limitations imposed by the policy rules. Since minor children and spouses are allowed to travel with the eligible migrant, the study focuses attention on the impact of migration on non-migrant parents, siblings, and nieces and nephews of the applicant. Thus their finding of 
no statistically significant effects of migration on the education of children left behind may in part be explained by the inherently more distant relationship between children and migrants in their study. Similarly, Gibson et al. (2011a) find no statistically significant effects of migration on the physical or mental health of older adult household members left behind, but due to nature of the experiment, not all are parents of the migrant applicant.

The advantage of such trials also lies in a methodological contribution, as it allows researchers to gauge the importance of selection problems in observational studies. To this end, Gibson et al. (forthcoming) point out the quadruple selectivity problem inherent in most migration studies: first, households select into migration, second, households choose whether to migrate en masse or send some subset of members abroad, third, some emigrants choose to return home, and fourth, emigrants decide when to return, creating a further selection problem for those researchers examining the impact of the duration of the migration spell. Importantly, even studies that claim to address selection into migration using some of the methods outlined above do not typically deal with selection into whether the whole household migrates. Gibson et al. (forthcoming) use data from the Samoan Quota lottery to show that failure to address this double selectivity problem yields biased estimates of the impact of migration on families left behind.

Having examined methodological issues surrounding estimation of the impact of migration on families left behind, the next section reviews the results examining the effects of migration on non-migrant children in particular.

\section{EFFECTS ON CHILDREN LEFT BEHIND}




\subsection{Education}

It is now well accepted that international migration of a parent or family member can have both positive and negative effects on non-migrant children in the home country. First, there is the possibility that remittances sent from abroad will relax the household budget constraint and result in an increase in child schooling, child health, and a corresponding decrease in child labor. Several studies find evidence supporting this hypothesis (Cox-Edwards and Ureta, 2003; Alcaraz et al., 2012; Yang, 2008). Yet researchers have also recognized that parental migration inherently involves parental absence from the home that can have a negative impact on child outcomes which may outweigh the positive effect of remittances.

Consistent with this, Giannelli and Mangiavacchi (2010) find that parental migration has a negative impact on school attendance for children left behind in Albania. Since men are the ones to migrate in most contexts, much of the literature has focused on the father's contributions to the family and connects the resulting loss when he becomes a migrant to the literature on father absence more broadly (Lahaie et al., 2009; Antman, 2011c). ${ }^{2}$ Zoller Booth (1995) stresses the importance of a father's role as disciplinarian and figurehead when interpreting the detrimental effects of paternal labor migration on the school readiness of children in Swaziland. Lahaie et al. (2009) find that the migration of a caregiver-spouse is significantly associated with academic, behavioral and emotional problems for children left behind in Mexico.

Another possibility often explored in the literature is that the effects may differ based on age and gender of the child. Meyerhoefer and Chen (2011) find that parental labor migration in China is associated with a significant lag in the educational progress of girls; a finding they argue is due to shifting girls’ time allocation toward home production. Similarly, McKenzie and 
Rapoport (2011) find a negative effect of migration on schooling of older children left behind in Mexico and match this behavior to increased housework for girls and migration for boys. While Acosta (2011) finds evidence that remittances result in a fall in child wage labor in El Salvador, girls benefit from an increase in schooling while boys do not.

Some studies have also tried to distinguish effects based on the gender of the migrant parent, but since the extent of female migrants is limited in many countries, few studies have generated meaningful results. One exception is Cortes (2010) who is able to compare children of migrant fathers with children of migrant mothers in the Philippines. She finds that maternal migration has an overall negative effect on children's education and argues that maternal absence is more detrimental than paternal absence. Similarly, Jampaklay (2006) finds that long-term maternal absence negatively affects children's education in Thailand, while paternal absence does not.

Another important channel to consider is the possibility that one parent's international migration may also result in a change in bargaining power among household decision-makers if one parent travels abroad while the other remains in the source country. If parents have different preferences over goods, this might also affect the allocation of resources and thus outcomes for children. This type of mechanism would be in accordance with the evidence presented in Antman (2011a) showing that families with migrant household heads spend a smaller fraction of resources on boys relative to girls in both clothing and education. Antman (2010a) exploits longitudinal data to investigate whether this relationship is causal and finds support for the idea that when a household head migrates, families spend more on girls relative to boys, and once the household head returns, the reverse is true. This is consistent with a shift in bargaining power 
toward women when men migrate and a shift back toward men once they have returned to the household. While this result may appear surprising if one expects boys to be relatively advantaged in the household, these findings make sense in light of the growing evidence that increasing women's bargaining power results in improvements in girls' health outcomes and not boys (Thomas, 1994; Duflo, 2003).

A final channel through which parental migration may affect children left behind is closely related to the more extensive literature on the existence of a "brain gain" resulting from migration. ${ }^{3}$ This phenomenon might occur when the very prospect of migration encourages those in the home country to obtain more education or skills, even though many of them ultimately never migrate. On this topic there is mixed evidence, depending in part on the country of focus (Beine et al., 2011). Of the microeconomic studies on this topic, Boucher et al. (2005) find no significant impact of international migration on schooling investments for non-migrants in Mexico while deBrauw and Giles (2006) find a negative relationship between internal migration opportunities and high school enrollment in China. Kandel and Kao (2000) offer suggestive evidence that children of migrants have lower educational aspirations than children with less exposure to migration as a pathway to mobility. In contrast, Batista et al. (2007) find evidence that higher migration prospects at the individual level increase the probability of completing intermediate secondary school in Cape Verde.

In the family context, it may be that parental migration imparts particularly specialized information about the returns to schooling owing to the common background of parent and child and the parent's particular migration experience. Whether this type of effect might operate in practice would in principle depend on the relative returns to education in the home and destination countries, taking into account the fact that educational attainment is not perfectly 
translatable across borders. Thus, this would likely depend on the specific home country-source country pairing and could certainly impart a disincentive to invest in child schooling (Gibson and McKenzie, 2011).

As illustrated above, studies have found both positive and negative effects of migration on schooling and educational outcomes of children left behind. ${ }^{4}$ Those that find positive effects tend to stress the importance of migrant remittances that relax the household resource constraint while studies that find overall negative effects tend to argue that the detrimental effects of parental absence override any improvements in income. Another important distinction which might explain these divergent findings is the time elapsed since the migration event took place, something that is not always observable by the researcher. For instance, Antman (2011b) finds a negative effect of paternal migration on study hours for boys within the first year after the migration took place, when it might be too early to expect a positive effect from remittances to outweigh the father's absence from the home. In contrast, Antman (2011c) finds a positive effect of paternal migration on ultimate educational attainment for girls, an inherently longer-term outcome when migration may be expected to yield greater positive effects. Hanson and Woodruff (2003) find a similar positive effect of living in a household with an external migrant on the educational attainment of girls in Mexico. The gendered pattern of these results, however, may also be due to a shift in bargaining power as discussed above and explored in Antman (2010a).

\subsection{Health of Children Left Behind}

Compared with the extensive research on the effects of migration on child schooling highlighted above, much less is known about the health effects for children left behind. 
Hildebrandt and McKenzie (2005) find a positive effect of migration of at least one household member on child health in Mexico as measured by higher birth weights and lower infant mortality rates. At the same time, they find that migration is associated with lower health inputs for children left behind, including breastfeeding and vaccinations. Gibson et al. (2011b) exploit the migration lottery to New Zealand discussed above and find evidence that migration of a household member leads to worse diets and health outcomes for children left behind in Tonga, as measured by weight-for-age and height-for-age. However, Stillman et al. (2012) and Gibson et al. (2011b) use the same lottery program to document improvements in health outcomes for children that migrate, thus adding to the more extensive literature comparing health outcomes of migrants and natives.

Positive effects of migration on the health of remaining children have been documented in other contexts as well. Macours and Vakis (2010) present evidence that maternal migration has a positive impact on early cognitive development of children in Nicaragua, a finding they attribute to changes in income and maternal empowerment stemming from migration. Anton (2010) finds a positive effect of remittances on short-term and middle-term nutritional status of children in Ecuador as measured by weight-for-height and weight-for-age. Kanaiaupuni and Donato (1999) show a positive effect of migration and remittances on infant survival in Mexico in the longer term.

Further research in this area is needed to get a sense for whether the somewhat divergent results discussed here can be attributed to different settings or heterogeneous effects based on the ages of children involved.

\section{EFFECTS ON SPOUSES LEFT BEHIND}


The literature on the impact of migration on spouses left behind is largely focused on labor supply responses of female non-migrants, and can be thought of as a subset of the larger literature examining the labor supply responses of non-migrant household members. Researchers in this area stress the importance of the remittance channel for generating a positive income effect that would raise the reservation wage of non-migrants, and thus potentially decrease labor force participation. ${ }^{5}$ As in the discussion in section 3, however, it is important to recognize that remittance receipt is typically preceded by a period in which the migrant leaves the home and is (at least temporarily) not contributing to the household. In this case, it may be that the migration of the head of household could induce his spouse to enter the labor market. Thus, the impact of international migration on spouses may again come down to a question of short-and long-term effects. Of course, if the migrant is not successful in obtaining a regular job to generate remittances over and above his earning in the home country, a spouse might be induced to remain in the labor market over the longer term as well. Regardless, the overall impact remains an empirical question to which researchers have turned their attention.

Consistent with an overriding income effect stemming from remittances, most studies present evidence of a negative effect of migration on labor supply of non-migrants. This relationship is robust across a wide range of settings. Grigorian and Melkonyan (2011) find a decrease in hours of work in Armenia for those households receiving remittances from migrants abroad. Kim (2007) shows that remittance income reduces labor market participation for nonmigrants in Jamaica. Rodriguez and Tiongson (2001) find that migrants reduce the labor participation and hours of work of non-migrants in the Philippines. Funkhouser (1992) finds that remittances have a negative effect on labor force participation in Nicaragua. 
In addition, some studies focus more directly on the labor supply responses of women left behind. Amuedo-Dorantes and Pozo (2006) find that remittances are accompanied by a drop in women’s labor supply in informal and nonpaid work in rural areas of Mexico. Lokshin and Glinskaya (2009) show that male migration negatively affects the labor market participation of women left behind in Nepal.

As women may be more likely to work without pay, it is also important to distinguish between different types of work. Mendola and Carletto (2009) find that having a migrant abroad decreases the paid labor supply of women in Albania while increasing their supply of unpaid work. Binzel and Assaad (2011) explore the effects of male international migration on the female labor supply of women left behind in Egypt, a country where labor force participation for women remains fairly low. They find a decrease in wage work for women left behind, but find that women are more likely to be employed in unpaid family work and subsistence work, such as agricultural activities for the purpose of own consumption. Mu and van de Walle (2011) find similar results in China, where migration leads to a decrease in wage work and family work, but an increase in agricultural work by women.

Since labor supply often forms the basis for individual earnings, these results only scratch the surface of the potential long-term economic effects of migration on spouses left behind. If bargaining power is rooted in relative income shares of household members, male migration may result in a loss in bargaining power for women through its effects on labor supplied outside the home, as hypothesized in Binzel and Assaad (2011). This represents an important extension of the literature on the impact of migration on families left behind and should be explored further.

\section{EFFECTS ON PARENTS LEFT BEHIND}




\subsection{Overview}

Another critical relationship for policymakers to understand is the impact of adult children's migration on non-migrant parents remaining in the home country. This is particularly true given the rapid aging of the population in most developing countries and the continued reliance on children for support in old-age. The context is important because international migration is often thought to boost earnings for migrants who may then remit more to parents at home. At the same time, the migrant may be restricted from traveling home and providing personal care for the elderly parent. This may act as an especially hard constraint for unauthorized migrants. These stylized facts raise several important policy questions: How does migration affect contributions and time assistance to aging parents? How can changes in their contributions be traced to impacts on their overall health and well-being? Do children remaining in the home country compensate for the absence of their migrant siblings?

\subsection{Contributions in Time and Money}

Despite the important policy questions raised by the incidence of migration and its impacts on non-migrant elderly dependents, there are still few studies that consider these relationships. Again, a critical stumbling block is proper identification of these effects, that is, tying outcomes directly to migration. Individuals and families select into migration. Thus having a migrant child may be correlated with other unobserved variables that are actually driving the relationship between migration and the outcome variable of interest. For instance, a bad economic shock may lead an individual to migrate and also to contribute less to his parents. Missing data on all transfers between children and parents also poses a significant challenge to researchers because migration may in part be funded by families in the home country and what 
we might interpret as an increase in transfers could actually be a simple repayment. This would be consistent with Stark’s (1991) model in which families insure migrants for taking on the risks associated with migrating in the short-run and in the long-run, the migrant repays the family members remaining in the home country.

Lucas and Stark (1985) develop empirical tests on the relationship between remittance behavior and home family characteristics to test between competing theories of the motivation to remit—pure altruism, pure selfishness, and what they term “tempered altruism or enlightened self-interest” where the family and migrant enter into a mutually beneficial contract that either provides a method of coinsurance against risks or investing in long-term projects. They find evidence for the latter. Rapoport and Docquier (2005) review these motivations and discuss the difficulties in using observed behavior to test competing theories underlying remittance behavior in the absence of sufficiently detailed data lacking in most studies.

Alaimo (2006) considers whether migrant parents receive more financial contributions from their children when one child migrates, but does not examine the intensive margin of time contributions. She also limits the sample to parents with no co-resident children over 18, which greatly reduces her sample since co-residence of adult children is highly prevalent in Mexico, as in other developing countries. She finds that parents of migrants are more likely to receive financial assistance and face similar chances of receiving time help as parents with no children in the U.S. While Antman (forthcoming) and the exercise below use the same data source as Alaimo (2006), the former does not exclude observations based on residency status and limits the sample to parents reporting difficulties with “Activities of Daily Living” in order to recover information on time contributions from children (discussed below). One could argue that these 
individuals are the most critical group of policy interest since they are the least independent and most likely to suffer without support of children.

\subsection{Do Parents Receive More Contributions when Children Migrate? The Case of Mexico}

\subsection{A. Overview}

This section considers how the U.S. migration of an adult child affects his elderly parent in Mexico on two important margins: the total financial contribution and the total hours of physical assistance received from all of his children. The focus on all children's transfers toward the parent is critical because it is reasonable to expect that individuals may respond to their siblings' behavior and this interaction may have effects on the welfare of their parents. If contributions are positively or negatively related across siblings, this would imply an amplification or dampening of the behavior of the migrant child. Since money and time contributions may be viewed as substitutes, the analysis must also account for the extent to which individual financial contributions respond to siblings' time contributions and vice versa.

Antman (forthcoming) considers the extent to which a migrant’s siblings will compensate for his absence by estimating best response functions for individual time and financial contributions as a function of siblings' time and financial contributions. The main question left unanswered, however, might also be the most critical for policymakers. Do total transfers to parents rise or fall when a child migrates? Of the relatively few papers that have addressed the specific issue of migrant transfers to parents in the home country ${ }^{6}$ it is not possible to conduct the thought experiment performed here where family behavior is observed both when one child migrates and stays home. To address this question, I use the estimates from the best response 
functions in Antman (forthcoming) to explore whether the findings point to an overall positive or negative effect of migration on contributions toward elderly parents from all of their children. By conducting a simulation where I exogenously switch the migrant status of one child in a family, we can observe the consequences of migration for elderly parents explicitly allowing for the possibility that siblings may compensate for migrant absence.

The data come from the Mexican Health and Aging Study (MHAS), a nationally representative panel data set of Mexicans born before 1950 with surveys in 2001 and 2003. ${ }^{7}$ The MHAS contains detailed information on financial transfers to the elderly respondent from his children and indicates whether children are currently in the U.S. As is common in the data sets used in the literature on elderly care, respondents reporting difficulty with "Activities of Daily Living" (ADLs) report how many hours in the last month their children help them with ADLs. ${ }^{8}$ Thus, the time contribution variable can be viewed as a measure of relatively critical physical support. The financial contribution variable reflects the monthly financial contribution from the child to the elderly parent. ${ }^{9}$ While the survey does not collect data on the earnings of children or transfers among children, it does collect basic information on a child's education, marital status, current migration status, and the number of his children, which are used as controls and for identification as detailed below.

\subsection{B. Estimating Best Response Functions}

Antman (forthcoming) uses the data to estimate best response functions for an individual child's contributions as a function of his siblings' contributions conditional on the migration decision. I assume that the time contribution must equal zero if the child migrates, ${ }^{10}$ thus there are only three equations to estimate: (1) a financial contribution equation for migrants which is a function 
of his siblings' total time and financial contributions, (2) a financial contribution equation for non-migrants which is a function of his siblings' total time and financial contributions and (3) a time contribution equation for non-migrants that is a function of siblings' total time and financial contributions. Each regression also includes a vector of control variables including characteristics of the individual child: a female dummy, birth order, age and age squared, four categorical variables describing education level, a married indicator and number of children. In addition, I also control for the following characteristics of the parent: a parental female dummy, parental married indicator, five indicators for difficulties with basic ADLs, parent's age and age squared, four categorical variables describing the parent's education level, a year dummy for taking the survey in 2003, and an indicator for residing in a more urban area. ${ }^{11}$

To address the simultaneity of siblings' contributions, siblings' characteristics are used as instrumental variables as they help to predict siblings' contributions but do not enter directly into the individual contributions equations. The identification assumption is that siblings’ characteristics only affect individual contributions through their impact on siblings’ contributions. This amounts to assuming that when deciding on how much to give their parents, children ultimately care only how much their siblings are actually contributing, rather than the siblings’ particular motivations for doing so.

Due to a high fraction of zeros in contributions, the best response estimates used to conduct the simulation below are based on IV two-step Tobit estimation of equations (1), (2), and (3). Antman (forthcoming) also compares these results with a variety of other estimates including those from IV linear and fixed effects specifications for those worried about unobserved heterogeneity at the family level. Estimates including a migrant selection term 
identified off of the siblings' characteristics in the model are also presented. The evidence points to individuals increasing their financial contributions in response to an increase in their siblings’ financial contributions, decreasing their time contributions in response to an increase in their siblings' time contributions, and decreasing their financial contributions in response to an increase in siblings' time contributions.

\subsection{Simulation}

The main question left unanswered is whether parents receive more or less contributions as a result of a child's migration. The answer lies in solving the best response functions simultaneously and obtaining the equilibrium contributions which represent the fixed point. To do this, I consider a family of seven siblings ${ }^{12}$ with median-level characteristics and draw a sample of 800 errors from a normal distribution with mean zero and variance equal to that found in the sample populations based on the estimated standard deviations from the three best response functions. To find the fixed point, I first make a guess for the initial contributions in time and money for all siblings. I then evaluate what the model predicts for each individual's contribution based on his sibling's contributions, the estimated coefficients, the median values for seven-sibling families and the randomly drawn error terms in the case where one child migrates and the case where all children remain in Mexico. If these predicted values match the initial guesses, then I have arrived at the equilibrium contributions; if they have not, I revise my guess for the value of each sibling's contribution accordingly and repeat the exercise with the

new guess. ${ }^{13}$ I then compare the equilibrium contributions toward elderly parents under the migration and non-migration scenarios across the 800 simulated observations.

[Table 1 about here] 


\subsection{Results}

Are parents better off when one child migrates? Table 1 answers this question by simulating contributions to the elderly parent in the case where one child migrates to the U.S. and the case where all children remain in Mexico. Most noteworthy is the fact that total hours of care to the elderly parent fall from 60 to 56 hours showing an unambiguous drop in time contributions that is statistically significant at the 1 percent level. At the same time, the difference in total financial contribution is not statistically different (1723 versus 1701 as a migrant family). While the potential migrant contributes less on average in terms of time and money when he is a migrant than when he is a non-migrant, the difference in financial contribution is small and not statistically significant. The fact that the time contributions of other siblings are not statistically different in either case suggests that the source of the drop in total time contribution is mainly due to the drop in the migrant's time contribution from 3.7 hours on average to zero. Thus, despite the presence of siblings that could compensate for the absence of the migrant child, the elderly parent receives less time contributions and no significant change in financial contributions overall when one child migrates.

\subsection{Effects on Health of Parents Left Behind}

If children's migration can be thought to affect the contributions to non-migrant parents in time and money, it is reasonable to ask whether children's migration also affects the health of elderly parents left behind. This matter is particularly important for policymakers in developing countries where populations are aging rapidly and the social safety net remains weak. Nevertheless, there are still few studies on this important topic, and even fewer that look at international migration in particular. 
Again, identification proves to be a major stumbling block for work in this area. The fact that migrants self-select raises the possibility that child migration and parental health may be correlated for a number of reasons other than a causal impact of child migration on parental health. For instance, causality may run in the opposite direction, as when a child responds to the ill health of a parent by migrating to raise money for medical treatment. In contrast, it may be that children with parents in ill health are less likely to migrate because they need to provide care for their parents. Indeed, Giles and Mu (2007) examine the impact of parental health on the probability of internal migration for adult children in China and find that younger adults are less likely to work as migrants when a parent is ill.

Other possibilities for a non-casual correlation between child migration and parental health can hold when migration is correlated with other factors that also affect elderly health. For instance, if migration is arduous, migrants may be more likely to be drawn from the upper tails of the health distribution. Since health is likely to be correlated within families, their parents are likely to be in better than average health as well, leading to an upward bias in observational studies of the effect of child migration and parental health.

Kuhn et al. (2011) address selection issues like these with a propensity score matching approach to examine the effects of internal migration of adult children on the health of elderly parents left behind in Indonesia. They find evidence of a positive link between child migration and parental health. Again, this methodology hinges on the assumption that migrant selection is based on observables, and is subject to the potential for bias if there are unobserved factors affecting children's migration and parental health. 
In contrast, Antman (2010b) looks at international migration from Mexico to the U.S. and finds that parents with at least one child in the U.S. on average have worse self-reported physical and mental health and are more likely to suffer from a heart attack or stroke. Antman (2010c) investigates whether this is in fact a causal relationship by using an instrumental variables approach to addresses the endogeneity of children's migration. Here, characteristics of children, such as the gender mix of the children of the elderly parent and the fraction of children that are married are used to instrument for having at least one migrant child. Overall, the evidence suggests that having a child migrate to the U.S. raises the probability that the elderly non-migrant parent will be in poor health. Antman (2010c) offers some suggestive evidence that the negative impact of children's migration on mental health may be responsible for deteriorating physical health, raising the possibility that resulting social isolation of elderly parents when their children migrate may be an important mediating factor. ${ }^{14}$

\section{CONCLUDING REMARKS}

This chapter has reviewed the literature on the impact of migration on family members left behind, with a focus on those most dependent on the migrant for support-his children, spouse, and parents.

The extensive research into the effects of migration on children's education points to both positive and negative effects, with researchers typically arguing that either remittances or parental absence, respectively, are outweighing other effects on the outcome of interest. In addition, there is some evidence of an incentive (or disincentive) effect due to the prospects of migrating, but whether this effect is positive or negative seems to depend on the specific pairing of source and destination countries. Another caveat to consider in this line of research is the time 
elapsed since the migration episode since effects may be more heavily weighted toward costs to families in the short-run, with returns coming later on.

As more women begin to migrate worldwide, further research should explore how effects differ by gender and dig deeper into how migration affects spouses and partners. In particular, additional studies should examine the effects of migration on intra-household bargaining power and outcomes reflecting relationship quality such as divorce. Researchers should also continue to expand the set of countries and settings under examination. The focus on Mexico-U.S. migration, while important, should be in proper proportion, as it is not likely to be representative of the pattern of migration observed elsewhere around the world.

Another important avenue for further research in this area should involve isolating mechanisms hinted at in prior research. To date, most studies continue to focus on estimation of an overall or net effect of migration on outcomes, rather than decomposing the effects to understand the underlying mechanisms. In part, this is due to data limitations which generally do not allow researchers to disentangle and quantify the multitude of effects coinciding with a migration episode. Thus, new and more detailed data sources should be developed to aid in this effort.

Data limitations may also be at the heart of the more limited research into the effects of migration on health outcomes for children as well as outcomes for aging parents. There is far too little evidence from too few countries to judge whether the studies reviewed here are typical of a more widespread pattern. Nevertheless, the results presented here on the detrimental impact of migration on time contributions and health outcomes for elderly parents pose real cause for concern. Further research should explore these relationships in other countries and with a wider 
variety of health outcomes. Policymakers should pay close attention as the system of social insurance may need to adapt considerably given that migration may place traditional support structures in jeopardy. Given the vulnerability of elderly populations in developing countries, these results suggest that governments and institutions in sending communities should be more concerned about the potentially detrimental consequences of migration for their own elderly populations. 


\section{REFERENCES}

Acosta, Pablo (2011), 'School attendance, child labour, and remittances from international migration in El Salvador', Journal of Development Studies, 47(6): 913-36.

Alaimo, Veronica (2006), 'The role of migration in family transfers: Is there a trade-off between time and money assistance?’ Mimeo, University of Illinois at Urbana-Champaign, Urbana, IL, USA.

Alcaraz, Carlo, Daniel Chiquiar and Alejandrina Salcedo (2012), 'Remittances, schooling, and child labor in Mexico’, Journal of Development Economics, 97(1): 156-65.

Amuedo-Dorantes, Catalina, Annie Georges and Susan Pozo (2008), 'Migration, remittances and children’s schooling in Haiti', IZA Discussion Paper 3657, Institute for the Study of Labor, Bonn.

Amuedo-Dorantes, Catalina and Susan Pozo (2006), 'Migration, remittances, and male and female employment patterns’, American Economic Review, 96(2): 222-26.

Amuedo-Dorantes, Catalina and Susan Pozo (2010), 'When do remittances facilitate asset accumulation? The importance of remittance income uncertainty’, Mimeo, San Diego State University, San Diego, CA, USA.

Antman, Francisca M. (2010a), 'International migration, spousal control, and gender discrimination in the allocation of household resources’, University of Colorado at Boulder Department of Economics Working Paper No. 10-15. Boulder, CO, USA.

Antman, Francisca M. (2010b) 'Adult child migration and the health of elderly parents left behind in Mexico’, American Economic Review, 100(2): 205-08. 
Antman, Francisca M. (2010c), 'How does adult child migration affect the health of elderly parents left behind? Evidence from Mexico’, University of Colorado Population Center Working Paper No. POP2011-09. Boulder, CO, USA.

Antman, Francisca M. (2011a) 'International migration and gender discrimination among children left behind', American Economic Review, 101(3): 645-49.

Antman, Francisca M. (2011b) 'The intergenerational effects of paternal migration on schooling and work: What can we learn from children's time allocations?' Journal of Development Economics, 96(2): 200-08.

Antman, Francisca M. (2011c) 'Gender, educational attainment and the impact of parental migration on children left behind', University of Colorado at Boulder Department of Economics Working Paper No. 08-02. Boulder, Colorado, USA.

Antman, Francisca M. (forthcoming), 'Elderly care and intrafamily resource allocation when children migrate', Journal of Human Resources.

Anton, Jose-Ignacio (2010), 'The impact of remittances on nutritional status of children in Ecuador', International Migration Review, 44(2): 269-299.

Batista, Catia, Aitor Lacuesta and Pedro C. Vicente (2007), 'Brain drain or brain gain? Micro evidence from an African success story', IZA Discussion Paper 3035, Institute for the Study of Labor, Bonn. 
Beine, Michel, Frederic Docquier and Hillel Rapoport (2011), 'Brain drain and human capital formation in developing countries: Winners and losers’, The Economic Journal. 118: 631-652.

Binzel, Christine and Ragui Assaad (2011), ‘Egyptian men working abroad: Labor supply responses by the women left behind', Labour Economics, 18(S1): S98-S114.

Boucher, Steve, Oded Stark and Edward J. Taylor (2005), ‘A gain with a drain? Evidence from rural Mexico on the new economics of the brain drain', Department of Agricultural and Resource Economics, University of California, Davis Working Paper No. 05-005. Davis, CA, USA.

Cortes, Patricia (2010), 'The feminization of international migration and its effects on the children left behind: Evidence from the Philippines’, Working Paper. Boston University School of Management. Boston, MA, USA.

Cox-Edwards, Alejandra and Manuelita Ureta (2003), 'International migration, remittances and schooling: Evidence from El Salvador', Journal of Development Economics, 72(2): 42961.

deBrauw, Alan and John Giles (2006), 'Migrant opportunity and the educational attainment of youth in rural China’, IZA Discussion Paper 2326, Institute for the Study of Labor, Bonn.

Duflo, Esther (2003) 'Grandmothers and granddaughters: Old-age pensions and intrahousehold allocations in South Africa', The World Bank Economic Review, 17(1): 1-25. 
Funkhouser, Edward (1992) 'Migration from Nicaragua: Some recent evidence’, World Development, 20(8): 1209-18.

Giannelli, Gianna Claudia and Lucia Mangiavacchi (2010), ‘Children’s schooling and parental migration: Empirical evidence on the 'left-behind' generation in Albania', Labour, 24: 76-92.

Gibson, John and David McKenzie (2011) ‘Eight questions about brain drain’, Journal of Economic Perspectives 25(3): 107-12.

Gibson, John, David McKenzie and Steven Stillman (2011a), 'The impacts of international migration on remaining household members: Omnibus results from a migration lottery program’, The Review of Economics and Statistics, 93(4): 1297-1318.

Gibson, John, David McKenzie and Steven Stillman (2011b), 'What happens to child health when migration splits households? Evidence from a migration lottery program', Food Policy, 36(1): 7-15.

Gibson, John, David McKenzie and Steven Stillman (forthcoming), ‘Accounting for selection and duration-dependent heterogeneity when estimating the impact of emigration on incomes and poverty in sending areas', Economic Development and Cultural Change.

Giles, John and Ren Mu (2007), 'Elderly parent health and the migration decisions of adult children: Evidence from rural China’, Demography, 44(2): 265-88. 
Grigorian, David A. and Tigran A. Melkonyan (2011), 'Destined to receive: The impact of remittances on household decisions in Armenia', Review of Development Economics, 15(1): 139-53.

Hanson, Gordon H. and Christopher Woodruff (2003), 'Emigration and educational attainment in Mexico’, Mimeo, University of California San Diego. San Diego, CA, USA.

Hildebrandt, Nicole and David J. McKenzie (2005), 'The effects of migration on child health in Mexico’, Economia 6(1): 257-289.

Jampaklay, Aree (2006), ‘Parental absence and children’s school enrolment: Evidence from a longitudinal study in Kanchanaburi, Thailand’, Asian Population Studies, 2(1): 93-110.

Kanaiaupuni, Shawn Malia and Katharine M. Donato (1999), 'Migradollars and mortality: The effects of migration on infant survival in Mexico’, Demography, 36(3): 339-53.

Kandel, William and Grace Kao (2000), 'Shifting orientations: How U.S. labor migration affects children’s aspirations in Mexican migrant communities', Social Science Quarterly, 81(1): 16-32.

Kim, Namsuk (2007), 'The impact of remittances on labor supply: The case of Jamaica’, World Bank Policy Research Working Paper 4120, Washington, DC, USA.

Kuhn, Randall (2006), ‘The effect of fathers' and siblings’ migration on children’s pace of schooling in Bangladesh', Asian Population Studies, 2(1): 69-92.

Kuhn, Randall S., Bethany Everett and Rachel Silvey (2011), ‘The effects of children’s migration on elderly kin’s health: A counterfactual approach’, Demography, 48(1): 183209. 
Lahaie, Claudia, Jeffrey A. Hayes, Tinka Markham Piper and Jody Heymann (2009), 'Work and family divided across borders: The impact of parental migration on Mexican children in transnational families’, Community, Work and Family, 12(3): 299-312.

Lokshin, Michael and Elena Glinskaya (2009), 'The effect of male migration on employment patterns of women in Nepal', The World Bank Economic Review, 23(3): 481-507.

Lucas, Robert E. and Oded Stark (1985), ‘Motivations to remit: Evidence from Botswana’, Journal of Political Economy, 93(5): 901-18.

Macours, Karen and Renos Vakis (2010), 'Seasonal migration and early childhood development', World Development, 38(6): 857-69.

McKenzie, David and Hillel Rapoport (2011), 'Can migration reduce educational attainment? Evidence from Mexico’, Journal of Population Economics, 24(4): 1331-58.

Mendola, Mariapia and Gero Carletto (2009), 'International migration and gender differentials in the home labor market: Evidence from Albania’, World Bank Policy Research Working Paper 4900, Washington, DC, USA.

Mergo, Teferi (2011), 'The effects of international migration on source households: Evidence from DV lottery migration', The Selected Works of Teferi Mergo available at: http://works.bepress.com/teferi_mergo/1 (accessed 12 January 2012).

Meyerhoefer, Chad D. and C.J. Chen (2011), 'The effect of parental labor migration on children's educational progress in rural China', Review of Economics of the Household, 9(3): 379-96. 
Mu, Ren and Dominique van de Walle (2011), 'Left behind to farm? Women’s labor reallocation in rural China', Labour Economics, 18(S1): S83-S97.

Rapoport, Hillel and Frederic Docquier (2005), ‘The economics of migrants’ remittances’, IZA Discussion Paper 1531, Institute for the Study of Labor, Bonn.

Reyes, Belinda I. (1997), 'Dynamics of immigration: Return to western Mexico’, Public Policy Institute of California, San Francisco, CA, USA.

Rodriguez, Edgard R. and Erwin R. Tiongson (2001), ‘Temporary migration overseas and household labor supply: Evidence from urban Philippines’, International Migration Review, 35(3): 709-25.

Stark, Oded (1991) The Migration of Labor, Cambridge, MA, USA: Basil Blackwell, Inc, pp. 216-20.

Stillman, Steven, John Gibson and David McKenzie (2012), 'The impact of migration on child health: Experimental evidence from a migration lottery program’, Economic Inquiry, 50(1): 62-81.

Thomas, Duncan (1994), 'Like father like son; like mother like daughter: Parental resources and child height', Journal of Human Resources, 29(4): 950-88.

Yang, Dean (2008), 'International migration, remittances and household investment: Evidence from Philippine migrants’ exchange rate shocks’, The Economic Journal 118: 591-630.

Zoller Booth, Margaret (1995), 'Children of migrant fathers: The effects of father absence on Swazi children's preparedness for school', Comparative Education Review, 39(2): 195210. 


\section{NOTES}

${ }^{1}$ Reyes (1997) provides evidence of the extent of temporary migration from Mexico to the U.S. Please see the chapter on circular migration for further discussion.

${ }^{2}$ A natural question to ask is how households with a migrant father abroad compare to households with a single (female) head. To my knowledge, there are no studies comparing outcomes for these two groups.

${ }^{3}$ See Gibson and McKenzie (2011) for a review of the findings from the "brain drain” and "brain gain” literature.

4 To my knowledge, no studies examine the impact on child happiness, crime, or children's future income.

${ }^{5}$ Again, the endogeneity of migration and remittance receipt remains the critical identification problem, as the same factors which predict migration may also affect labor supply of nonmigrants.

${ }^{6}$ See for example Alaimo (2006) and Lucas and Stark (1985).

7 The MHAS is joint project between Mexico’s statistical agency, INEGI, and researchers at the Universities of Pennsylvania, Maryland, and Wisconsin. It is publicly available at http://www.mhas.pop.upenn.edu/

${ }^{8}$ These include basic ADLs such as getting in and out of bed, bathing oneself, using the toilet, eating, and walking across a room as well as "instrumental” ADLs such as preparing a hot meal, shopping for groceries, taking medications if needed, and managing money.

${ }^{9}$ See Data section of Antman (forthcoming) for more details.

${ }^{10}$ Only one percent of current U.S. migrants in the sample are reported to give any time to parents in Mexico.

${ }^{11}$ See Antman (forthcoming) for descriptive statistics.

12 The median number of children among parents with at least one child in the U.S. is seven. 
${ }^{13}$ In practice, I define convergence to be achieved if the predicted value of the younger sibling's contribution is within 1 peso of the guess for his financial contribution and within 0.1 hour of his time contribution. The revised guess is defined to be half of the difference between the guess and the predicted value.

${ }^{14}$ The mental health measure used here is a self-reported indicator of poor mental health that is equal to one if the respondent reports having felt lonely, sad, or depressed for the majority of the week prior to the survey. 